\title{
Production of dietary feed supplements enriched in microelements in a pilot plant biosorption system
}

\author{
Z. Witkowska ${ }^{1}$ P. Rusek ${ }^{2}$ A. Witek-Krowiak ${ }^{3}$ K. Chojnacka ${ }^{1}$ L. Tuhy ${ }^{1}$. \\ M. Samoraj ${ }^{1}$
}

Received: 25 June 2015/Revised: 16 November 2015/Accepted: 6 February 2016/Published online: 24 February 2016

(C) The Author(s) 2016. This article is published with open access at Springerlink.com

\begin{abstract}
In this work, biosorption was used as a method to enrich biomass (soybean meal) with microelements [such as $\mathrm{Zn}(\mathrm{II}), \mathrm{Cu}(\mathrm{II}), \mathrm{Mn}(\mathrm{II})$ and $\mathrm{Fe}(\mathrm{II})]$ that are essential in livestock nutrition to produce dietary feed supplements. The biosorption process was carried out in a specially designed pilot plant system with two-column reactors according to the principles of the eco-friendly effluent-free technology. The applicative parts of products and innovative biological feed supplements were produced for zootechnical tests on animals (hens, goats and fatteners). Multielemental analysis showed a multiple increase in the content of each microelement in the soybean meal after biosorption [of $\mathrm{Zn}(\mathrm{II})-168$ times, $\mathrm{Cu}(\mathrm{II})-179$ times, $\mathrm{Mn}(\mathrm{II})-62$ times and $\mathrm{Fe}(\mathrm{II})-50$ times]. The process was analyzed in terms of technological indicators and preliminary economic analysis, including the cost of materials, labor costs and depreciation of the equipment used. It was found that the cost of supplementation of $1 \mathrm{~kg}$ of feed for laying hens and fattening pigs with the new preparation
\end{abstract}

Electronic supplementary material The online version of this article (doi:10.1007/s13762-016-0945-z) contains supplementary material, which is available to authorized users.

A. Witek-Krowiak

anna.witek@pwr.edu.pl

1 Department of Advanced Material Technologies, Department of Chemistry, Wrocław University of Technology, Smoluchowskiego 25, 50-372 Wrocław, Poland

2 Fertilizer Research Institute, al. Tysiąclecia Państwa Polskiego 13a, 24-110 Puławy, Poland

3 Division of Chemical Engineering, Department of Chemistry, Wrocław University of Technology, Norwida 4/6, 50-373 Wrocław, Poland enriched with $\mathrm{Cu}(\mathrm{II})$ and manufactured on a technical scale was around $\$ 0.393$.

Keywords Biomass - Cost analysis - Feed additives · Micronutrients $\cdot$ Technical scale

\section{Introduction}

Biosorption is a natural property of non-living matter of biological origin that is capable of binding cations and anions at their surface (Chojnacka 2010; Doshi et al. 2007). The application of biosorbents in the water and sewage treatment process appears to be a viable alternative to the application of the traditional sorbents (like activated carbon). The materials of biological origin are characterized by a relatively high sorption capacity, and are at the same time much cheaper because they constitute waste material from various industries (e.g., foodstuffs industry or processing of wood) or the easily available biomass derived from the environment (Witek-Krowiak et al. 2013a, b; Podstawczyk et al. 2014; Zhang et al. 2015; Mishra et al. 2015).

The main purpose in using biosorption is the treatment of aqueous solutions and the removal of pollutants that are dangerous for the environment by means of materials that have a large sorption capacity. Agricultural wastes or industrial wastes can be used as biosorbents. The biosorption process can also be used for the purpose of enriching the waste material of plant origin with essential cations (micro- and macroelements) to make it a component of a balanced diet, i.e., feed for animals or an enriched fertilizer for plants (Chojnacka et al. 2009; Chojnacka 2013). This technique allows for producing safer and greener feed additives as carriers of micronutrients in livestock feeding. 
Table 1 Examples of biosorption process in semi-technical scale

\begin{tabular}{|c|c|c|c|c|c|c|}
\hline Patent no. & Process & Reactor & Biosorbent & Cations & $c_{\mathrm{Me}+}\left(\mathrm{mg} / \mathrm{dm}^{3}\right)$ & $\dot{\bar{V}(\mathrm{ml} / \mathrm{min})}$ \\
\hline \multirow[t]{3}{*}{ US 7,326,344 B2 } & \multirow{3}{*}{$\begin{array}{l}\text { Removal of } \mathrm{Cu}^{2+}, \mathrm{Fe}^{3+} \\
\mathrm{Zn}^{2+} \text { ions from industrial } \\
\text { effluents }\end{array}$} & \multirow[t]{3}{*}{ Column bed } & \multirow{3}{*}{$\begin{array}{l}\text { Any immobilized } \\
\text { microorganisms capable } \\
\text { of binding metal ions }\end{array}$} & $\mathrm{Cu}^{2+}$ & $\begin{array}{l}c_{0}=200-300 \\
c_{\mathrm{k}}<1\end{array}$ & \multirow[t]{3}{*}{694} \\
\hline & & & & $\mathrm{Fe}^{3+}$ & $\begin{array}{l}c_{0}=1-32 \\
c_{\mathrm{k}}<5\end{array}$ & \\
\hline & & & & $\mathrm{Zn}^{2+}$ & $\begin{array}{l}c_{0}=6-80 \\
c_{\mathrm{k}}<3\end{array}$ & \\
\hline US 2008/0009054 A1 & $\begin{array}{l}\text { Removal of } \mathrm{Cu}^{2+} \text { ions from } \\
\quad \text { solutions }\end{array}$ & Column bed & $\begin{array}{l}\text { A new strain of } \\
\text { immobilized bacteria } \\
\text { Bacillus sp. }\end{array}$ & $\mathrm{Cu}^{2+}$ & $\begin{array}{l}c_{0}=7.3 \\
c_{\mathrm{k}}<1\end{array}$ & 400 \\
\hline \multirow[t]{6}{*}{ US 4,732,681 } & \multirow{6}{*}{$\begin{array}{l}\text { Removal of } \mathrm{Ni}^{2+}, \mathrm{Cu}^{2+} \\
\mathrm{Zn}^{2+}, \mathrm{Pb}^{2+}, \mathrm{Cd}^{2+}, \mathrm{Cr}^{6+} \\
\text { ions from solutions }\end{array}$} & \multirow[t]{6}{*}{ Stirred tank } & \multirow{6}{*}{$\begin{array}{l}\text { Biomass of fungi } \\
\text { Cladosporium } \\
\text { cladosporioides }\end{array}$} & $\mathrm{Ni}^{2+}$ & $\begin{array}{l}c_{0}=10 \\
c_{\mathrm{k}}=2\end{array}$ & \multirow[t]{6}{*}{ - } \\
\hline & & & & $\mathrm{Cu}^{2+}$ & $\begin{array}{l}c_{0}=10 \\
c_{\mathrm{k}}=0.7\end{array}$ & \\
\hline & & & & $\mathrm{Zn}^{2+}$ & $\begin{array}{l}c_{0}=10 \\
c_{\mathrm{k}}=2.55\end{array}$ & \\
\hline & & & & $\mathrm{Cd}^{2+}$ & $\begin{array}{l}c_{0}=20 \\
c_{\mathrm{k}}=1.5\end{array}$ & \\
\hline & & & & $\mathrm{Pb}^{2+}$ & $\begin{array}{l}c_{0}=10 \\
c_{\mathrm{k}}=0.1\end{array}$ & \\
\hline & & & & $\mathrm{Cr}^{6+}$ & $\begin{array}{l}c_{0}=10 \\
c_{\mathrm{k}}=3.75\end{array}$ & \\
\hline
\end{tabular}

$c_{0}$ : initial concentration of metal ions; $c_{\mathrm{k}}$ : final concentration of metal ions; $c_{\mathrm{Me}+}$ : concentration of cation; $\dot{V}$ : flow rate

Biosorption is a promising method that could be used in many environmental processes (Hood et al. 2013; Aytar et al. 2014; Mansuri et al. 2014), but it has been applied extremely rarely on a large scale. Biosorption can be carried out in a batch stirred tank reactor or in a dynamic system such as columns and fluidized reactor columns (Michalak et al. 2013). Literature reports the use of a stirred tank only on a laboratory scale. On a semi-technical and industrial scale, only columns are used (Jauberty et al. 2011). Biosorption columns for removal of heavy metals from wastewater are reported as potentially an important technology in rendering the production process cleaner (Reverberi et al. 2009). If microorganisms are used as biosorbents, they may be immobilized on a carrier (Verma et al. 2014; Pan et al. 2005). The use of microorganisms such as Bacillus pumilus is an exemplary clean technology high exhaustion of chrome for leather tanning. Biosorption of chromium with the use of varied biomass is a clean option in which chromium is absorbed to an acceptable limit ( $99.5 \%$ reduction in chromium with use Bacillus pumilus) (Kanagaraj et al. 2014).

Biomass might be regenerated for reuse by removing the bound metal ions and maintaining the continuity of the system by using two alternately working columns; while biosorption proceeds in a single column, the second column undergoes the desorption process. If metal ions are valuable, they may be subsequently recovered from the solution after desorption (Kratochvil and Volesky 1998).

In the available literature, there are descriptions of research on biosorption mainly on a laboratory scale. Several patents on the purification of aqueous solutions by the biosorption process on a pilot plant scale have been reported (Table 1). U.S. Patent No. 7,326,344 B2 uses the system of two to three biosorbers with a capacity of $100 \mathrm{dm}^{3}$, connected in a series. To reduce the initial concentration of metal ions in the solution process, a precipitation reactor is used or the $\mathrm{pH}$ of the extractant is increased before the solution is submitted to the first reactor. This solution is directed to the biosorbers. The reactors operate alternately. When the maximum biosorption capacity of the first reactor is reached, the solution is passed to the next. It is during this time that the first reactor regeneration of biomass occurs, which caused by an acidic solution. The U.S. Patent 2008/0009054 A1 describes a bioreactor with a capacity of $90 \mathrm{dm}^{3}$ for a culture of microorganisms, which also serves as a biosorber. The process is takes place in three steps: First, microorganisms are grown on the carrier and then bioaccumulationbiosorption of metal ions from the solution, and desorption of metal ions with an acidic solution (regeneration of the biomass) occur. Another U.S. Patent, 4,732,681, contains a description of the installation for biosorption in a system 
with three mixers in a row, in which the sequential purification of solutions in increasing metal ions concentrations was carried out. In each reactor, the residence time was $120 \mathrm{~min}$ and the concentration of biomass was $10 \mathrm{~g} /$ $\mathrm{dm}^{3}$. The biomass may then be regenerated for reuse after the removal of bound metal ions, for example by means of electrolysis or by extraction of the low $\mathrm{pH}$.

Currently, on the market there are no industrial installations for biosorption. The only manufacturer of systems for biosorption was BV Sorbex Inc. (Montreal, Canada). The company primarily offered biosorbents as well as biosorption systems (Biosorption Pilot Systems-BeePS). The installations on offer were used for the purification of aqueous solutions from dyes and heavy metal ions. As far as we know, the installations for biomass enrichment with desirable elements as a new concept of using biosorption have not been constructed yet. A new concept of producing feed additives with microelements introduced by biosorption was proposed in which biomass, which is a commonly used ingredient in compound feed, was the carrier of micronutrient ions (Witkowska et al. 2013). In the applications of biosorption described in the literature as a de facto method of solutions purification, the product is water purified from metal ions. In addition, the biomass is supposed to have a very high biosorption capacity. If the biosorption process is used for the production of feed additives with microelements, the product will be a biomass enriched in the desired elements. The application of innovative green and clean technology in feed additives production seems to be a point of interests in the development of safer foodstuffs.

The aim of the present work was the development of a new clean method for producing innovative biological feed additives containing microelements, thus demonstrating biosorption possibilities on a large scale_quarter-technical scale. New eco-friendly feed additives of the required composition, adapted to the nutritional needs of the different species of farm animals-hens, hogs and goatswere produced in a pilot installation. This research was carried out in the Department of Chemistry, Wroclaw University of Technology (March-May 2013).

\section{Materials and methods}

\section{Biosorbent: soybean meal}

The biosorbent selected for the study, which was non-living biomass of soybean meal, is a material traditionally used as a part of animal feed: (Glycine max L. Merr.; Ceral, Jawor, Poland). Soybean meal is an accepted biomass as a feed for animals (Decree of the Minister of Agriculture and Rural Development, 2007, OJ 2007, No. 2, pos. 24).
During the biosorption, biomass is enriched with micronutrients in a process based mainly on the sorption and ion exchange. Metal ions can be bound to different functional groups (carboxyl, amine, hydroxyl, etc.) that occur on cell walls. Before each experiment, the biomass was evenly ground into approximately 1-mm grain-size particles.

\section{Pilot plant biosorption system}

The installation consisted of water purification stations, a demineralized water reservoir, a reservoir for a solution of trace elements, two-column reactors for biosorption process with a capacity of $200 \mathrm{dm}^{3}$ each, a filter press, a dryer and a series of pumps and pipes (Fig. 1). Each of the reactors was equipped with a spray that allowed for a uniform application of microelements solution onto a bed of biomass.

Soybean non-living biomass (soybean meal) was enriched with $\mathrm{Cu}(\mathrm{II}), \mathrm{Zn}(\mathrm{II}), \mathrm{Fe}(\mathrm{II})$ and $\mathrm{Mn}$ (II) ions by biosorption, using $\mathrm{CuSO}_{4} \cdot 5 \mathrm{H}_{2} \mathrm{O}, \mathrm{ZnSO}_{4} \cdot 7 \mathrm{H}_{2} \mathrm{O}, \mathrm{FeCl}_{2}$ $4 \mathrm{H}_{2} \mathrm{O}$ and $\mathrm{MnSO}_{4} \cdot \mathrm{H}_{2} \mathrm{O}$ in the concentration of $500 \mathrm{mg} /$ $\mathrm{dm}^{3}$ for micronutrient ions.

Biosorption was performed in a single-component system, the process solution consisted of demineralized water and the inorganic salt of trace elements ( $\mathrm{Zn}, \mathrm{Cu}, \mathrm{Fe}$ or $\mathrm{Mn})$. In the first step of the process, demineralization of tap water in a water purification station was undertaken. Then it was directed into the first tank, which was warmed to ambient temperature. The water was then sent to a second tank equipped with a $\mathrm{pH}$-stat, where the solution of the trace elements (zinc, copper, iron or manganese) was prepared by adding an appropriate amount of demineralized water and dissolving salts of microelements. The $\mathrm{pH}$ of the solution was adjusted to 5.0 with $1 \mathrm{M} \mathrm{NaOH} / \mathrm{HCl}$ and was controlled by a pH-meter Mettler-Toledo InLab413 electrode with temperature compensation, maintaining the $\mathrm{pH}$ at a constant level during the process. At first, the sorption column was packed with soybean meal and then the solution containing microelements was fed to the column. The concentration of microelements in the feed was ca. $300 \mathrm{mg} / \mathrm{dm}^{3}$. The flow rate was $140 \mathrm{dm}^{3} / \mathrm{h}$. The process solution, rich in potassium ions, was returned to the tank, where after a $\mathrm{pH}$ adjustment it was redirected into the column. The enriched biomass of non-living biomass (soy meal) was directed to a filter press where it was dried to mechanically remove the residual process solution and reduce the cost of thermal drying. After the biomass had been drained, the solution was directed to the tank. The produced feed additive underwent drying in a sieve at $50{ }^{\circ} \mathrm{C}$, for $24 \mathrm{~h}$, to a moisture content not exceeding $12 \%$. At the time when the first column was being discharged, fresh biomass was placed in the second column, which was 
Fig. 1 Flow sheet of the experimental plant for biosorption processes $(1$ - water tank, 2-pump, 3micronutrient solution tank, 4 container helical agitator 5feeding pump, 6-sorption reactors, 7-spray nozzle, 8 sorption basket, 9-perforated bottom, 10-biomass grinder, 11 -water treatment plant, 12 impeller pump, 13-peristaltic pump, 14-filter press, 15dryer, 16-liquid fertilizer tank, $M S$ - micronutrient salts, $B I$ biomass, $R B$-enriched

biomass, $L F$-liquid fertilizer, $W$-water, $A$-eluent stream, $B$ - enriched biomass stream, $C$-press filtrate, $D$-eluent

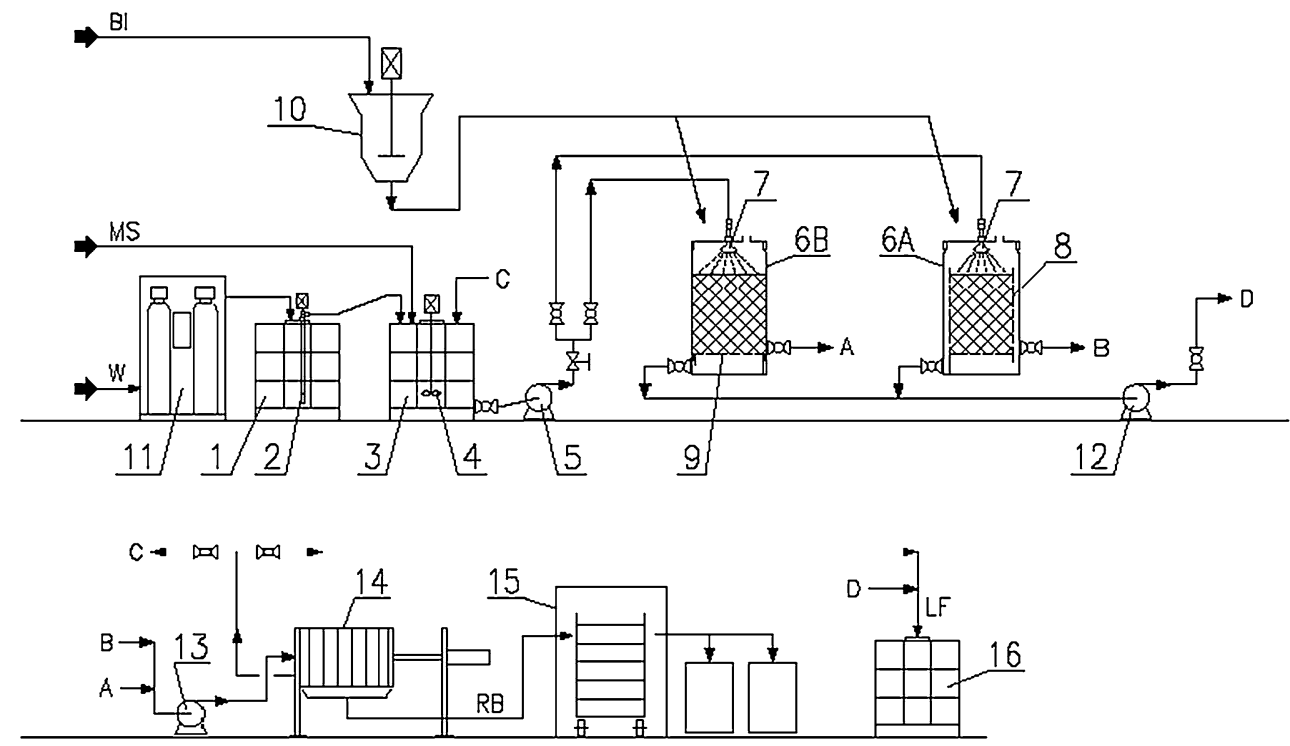

followed by a process that was carried out in a similar manner. During the process, samples of the solution were taken at the moment of them being discharged from the system. The biomass and the medium from the biosorption process were taken for analysis. The collected samples of biomass were averaged and mineralized. The solutions were sampled and also underwent an ICP-OES analysis (Varian Vista MPX, Australia). All the analyses were carried out according to PN EN ISO 17025 in the laboratory accredited by the Polish Centre for Accreditation (nr AB 696) and ILAC-MRA.

The obtained preparations were used as dietary feed supplements with microelements in the zootechnical studies on fatteners and goats, with the biofortification effect being brought, thus resulting in the biofortification effect (Witkowska et al. 2015).

\section{Results and discussion}

\section{Research strategy}

Currently, inorganic salts are the most commonly used microelement supplements of feed (Tuhy et al. 2013). Their application is disadvantageous in that they have a low bioavailability and in that the ions of microelements derived from the inorganic salts that they are likely to form insoluble complexes in the animal's gastrointestinal tract (microelement becomes unavailable for the organism) (Blanusa et al. 2005).

Organic micronutrient combinations, such as metal ion chelates, are more bioavailable than the inorganic salts (Tuhy et al. 2014). Chelates have a very high stability, which comes from stronger bonds connecting the metal ion to the ligand. Chelated micronutrients are used much less often than inorganic salts, which is due to their very high price, which is up to ten times higher than that of inorganic salts (Tuhy et al. 2014). There are also reports on the irritation of the gastrointestinal tract (Blanusa et al. 2005).

At present, the feed market does not offer an alternative to inorganic salts and organic chelates. In recent years, several papers have proposed/new formulations based on the biosorption process as a method of production of innovative feed additives with microelements (Fig. 2). These studies dealt with enriched biomass of macroalgae and microalgae (Michalak and Chojnacka 2009; Zielinska and Chojnacka 2010).

The effect of new formulations was tested on laying hens and fatteners. It has been shown that the new supplements improved the technological value of the carcass and the physical parameters of eggs, as well as the content of micronutrients in the edible parts of animals (Witkowska et al. 2013). Our previous feeding trials on goats have shown that the use of new formulation resulted in the enrichment of milk with trace elements. The use of biological additives causes the enrichment of milk with trace elements such as copper (about $8.2 \%$ ), manganese (29.2\%) and zinc (14.6\%) (Witkowska et al. 2015).

New formulations may provide an alternative to currently used supplements. It is because of the disadvantages of conventionally used feed supplements and a small amount of research on innovative formulations that basic research should be focused on the development of a new formulation. New feed additives based on the biosorption process would be characterized by a low price, good bioavailability, non-toxicity for animals and the environment (Witkowska et al. 2015). Additionally, this kind of material would not cause difficulties in redistributing in the 


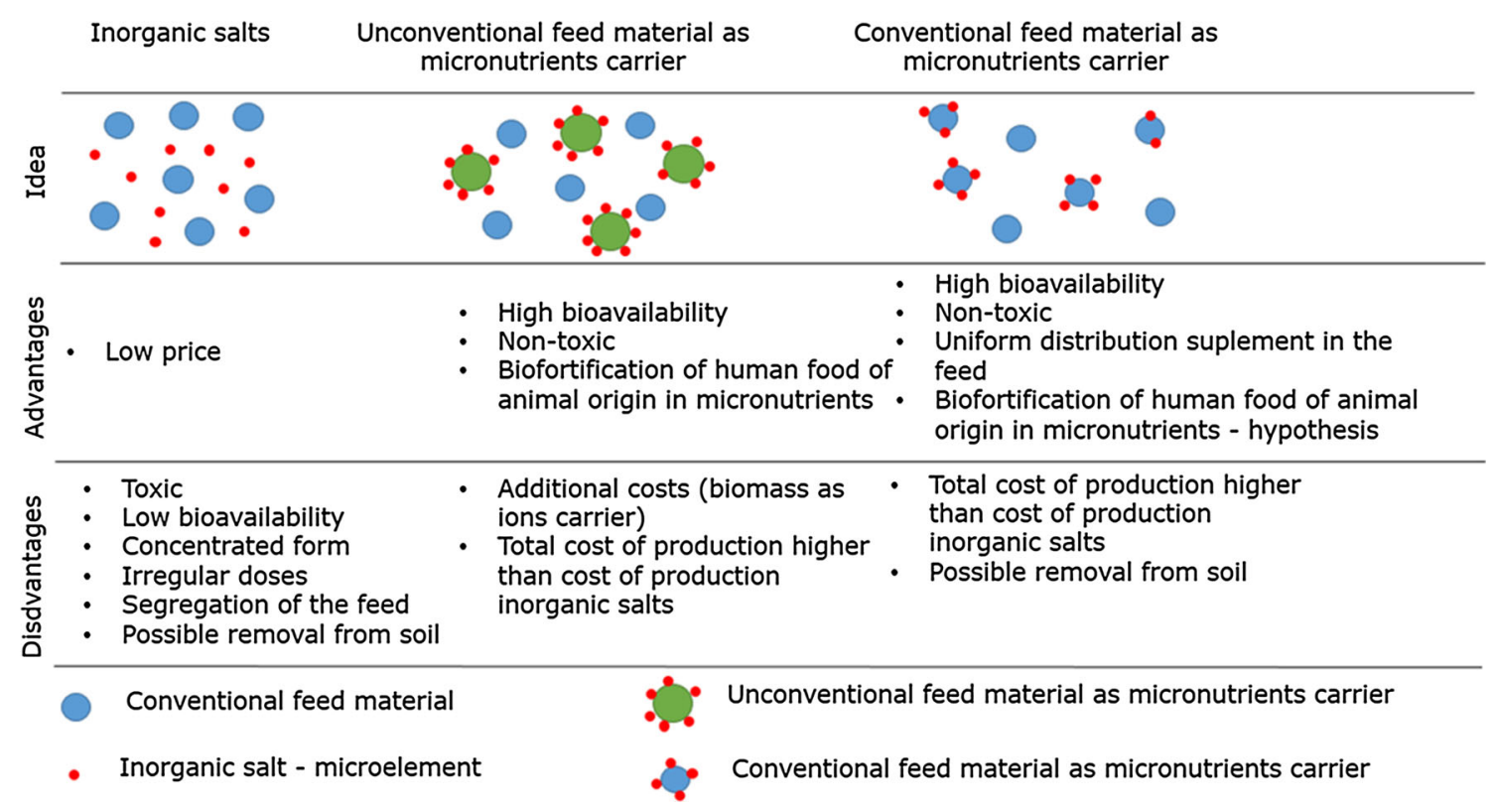

Fig. 2 Comparison of three concepts of feed enrichment in microelements

feed as well as would not go separation during the transport. The advantage would also be a neutral taste for animal preparation.

It is possible to obtain microelements from industrial wastewater streams. However, industrial wastewater contains other, often dangerous, substances which could be adsorbed simultaneously on the biomass. Hence, the use of this type of streams may carry the risk of producing feed additives of an uncontrolled composition. In the future, we will intend to search for a safe source of waste microelements. In the present work, we used model solutions because these were the first production tests in the new pilot plant biosorption system.

The previous comparison of the process in the stirred tank reactor and the column indicated that the column reactor was characterized by a significantly greater productivity while allowing efficient enrichment of biomass with microelements, the contents of which increased after biosorption 70-1000 times. On this basis, we proposed a pilot plant system for biosorption consisting of column reactors and using feed material as a biosorbent.

\section{Biosorption of microelement ions in the system of two-column reactors with a total bed capacity of $400 \mathrm{dm}^{3}$}

Figures 3 and 4 show the installation specially constructed to conduct biosorption as well as stimulate the feed additives manufacturing process. The process of biosorption carried out in the installation on a quarter-technical scale produced formulations prepared with trace elements
[Cu(II), Mn(II), $\mathrm{Zn}(\mathrm{II})$ and $\mathrm{Fe}(\mathrm{II})]$ based on biomass of soybean meal. Table 2 shows the results of the analysis of the raw and enriched (preparation for animals) soybean meal. The multielemental analysis showed an increase in the content of each microelement ion in the biomass after biosorption. The content of $\mathrm{Cu}$ (II) increased 179 times (from 0.065 to $11.7 \mathrm{mg} / \mathrm{g}$ ), the content of $\mathrm{Zn}$ (II) 168 times (from 0.054 to $9.06 \mathrm{mg} / \mathrm{g}$ ), the content of $\mathrm{Fe}(\mathrm{II}) 50$ times (from 0.235 to $11.9 \mathrm{mg} / \mathrm{g}$ ), and that of $\mathrm{Mn}(\mathrm{II}) 62$ times (from 0.095 to $5.92 \mathrm{mg} / \mathrm{g}$ ).

During the production of the preparation with zinc, samples of the inlet and outlet solutions were taken. The samples were subjected to an ICP-OES analysis in order to monitor changes in the elemental composition of the process solution. The results clearly show that the binding of $\mathrm{Zn}$ (II) and $\mathrm{Cu}$ (II) occurs partly in accordance with the mechanism of ion exchange with $\mathrm{Ca}^{2+}, \mathrm{K}^{+}$and $\mathrm{Mg}^{2+}$ ions (Table 3). The observed release of ions from the surface of the sorbent may indicate a counter current diffusion process during biosorption. $\mathrm{K}(\mathrm{I})$ and $\mathrm{Mg}$ (II) ions were released in the largest amount, which represents approximately $75 \%$ of the ions leaving the surface of the biomass. Considering the amount of adsorbed ions $\mathrm{Zn}$ (II) and $\mathrm{Cu}$ (II) (179.8 and $182.4 \mathrm{mmol} / \mathrm{kg}$, respectively), the amount of exchanged ions is approximately 76 and $60 \%$ of the total quantity of ions that was bound with the sorbent.

In contrast to the biosorption on a large-laboratory scale in the fluid bed column, where the feed solution had a constant concentration, in the case of a quarter-technical scale biosorption, the solution discharged from the column was recycled in order to reduce the quantity of spent water. 


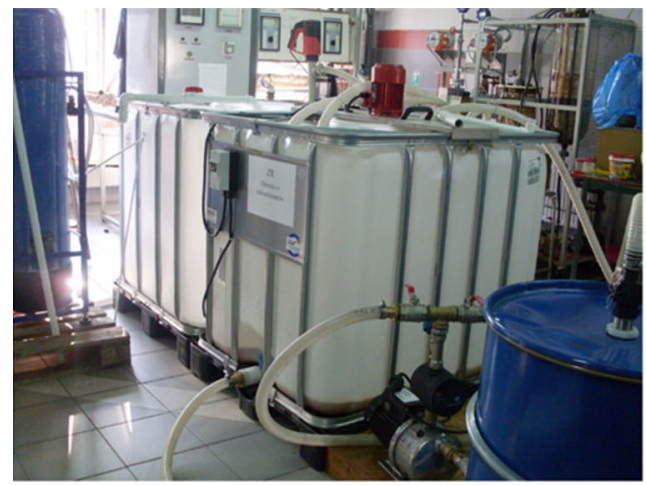

A

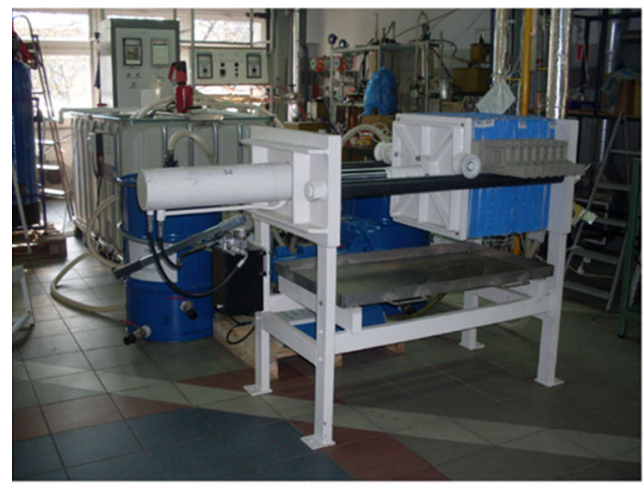

C

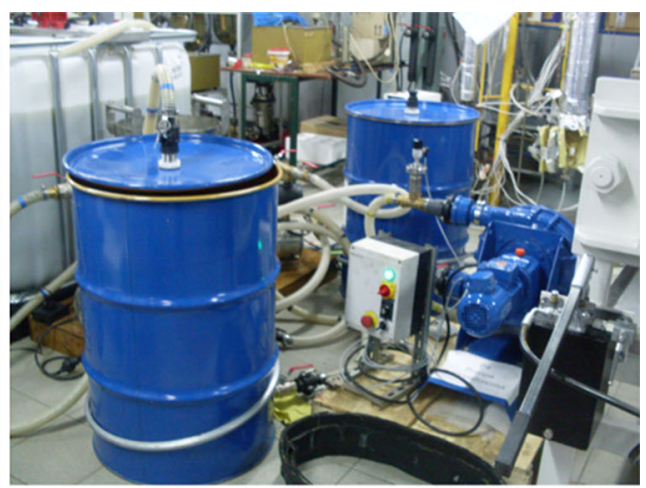

B

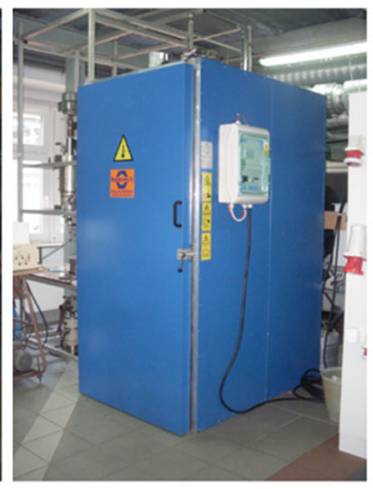

D

Fig. 3 Installation for the biosorption process. a Reservoir solution of micronutrients, b sorption columns with the system pumps, $\mathbf{c}$ filter press, d dryer

While micronutrients are binding to non-living biomass of soybean meal, alkaline earth metal ions are released to solution. Therefore, a liquid stream with potassium was obtained during the process. The solution after the biosorption may be used as a potassium liquid fertilizer. The main mechanism of biosorption process is the ion exchange, in particular with potassium and sodium ions and, to a lesser extent, calcium and magnesium (WitekKrowiak et al. 2013a; Davis et al. 2003).

Figure 5 shows the change in the concentration of $\mathrm{Zn}(\mathrm{II})$ during the process at the inlet and outlet. The initial concentration of $\mathrm{Zn}$ (II) in the solution was $351 \mathrm{mg} / \mathrm{dm}^{3}$. The mass of soybean meal placed in the column was $23.1 \mathrm{~kg}$. The ICP-OES analysis of the solution samples yielded a progressive decrease in the concentration of $\mathrm{Zn}$ (II) in the feed solution. This was caused by dilution at the outlet that was recycled to the system. Most of $\mathrm{Zn}$ (II) was sorbed in the first hours of the operation. With the passage of time, the concentration of $\mathrm{Zn}(\mathrm{II})$ in the process solution as it was leaving the column increased, reflecting the gradual saturation of the bed with zinc ions. Saturation of the bed occurred when the concentration of cations at the inlet was the same as at the outlet of the column. This occurred after $9 \mathrm{~h}$ of the biosorption process (that was carried out as described).
After the first and second hours of biosorption, the degree of the soybean meal enrichment with $\mathrm{Zn}$ (II) in the column from the feed solution was, respectively, 81.5 and $61.4 \%$. After another hour of the process, the degree of the removal of copper ions from the solution was smaller and amounted to 53.7, 48.5 and $23.4 \%$ after the third, fourth and fifth hours. In subsequent hours, ion binding was less than $10 \%$. This means that a bed of zinc ions binds very effectively during the first hour of the process. Within the next $3 \mathrm{~h}$, the process was moderately effective, but after some time, the ions were adsorbed to a smaller extent.

The multielemental analysis of the raw soybean meal showed that the biomass was rich in potassium $(2446.5 \mathrm{mg} / \mathrm{kg})$, whereas the sodium content was almost thirty times lower $(85.115 \mathrm{mg} / \mathrm{kg})$. It is for this reason that a large amount of potassium ions was released into the solution after the biosorption process. Suppl. Figure 1 shows the change in the potassium ion concentration in the solution leaving the column during the enrichment of soybean meal in the $\mathrm{Zn}$ (II) in the quarter-technical scale installation. To describe the process, Haldane's model was used, as reported in the available literature. This model describes the process of biosorption in a column reactor with the solution being recycled. Model parameters were chosen empirically (Suppl. Table 1). 


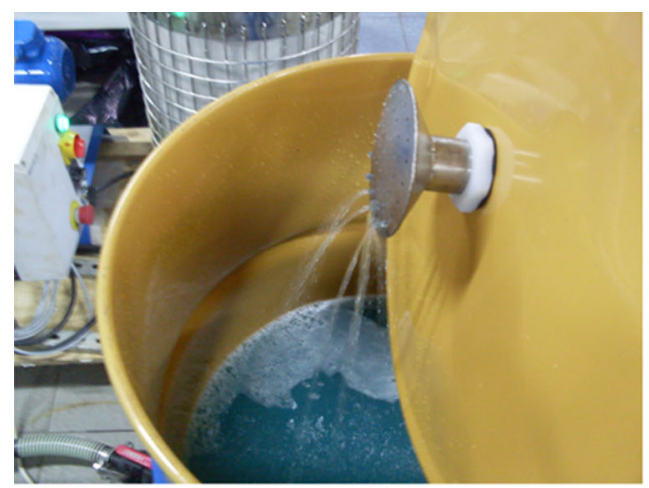

A

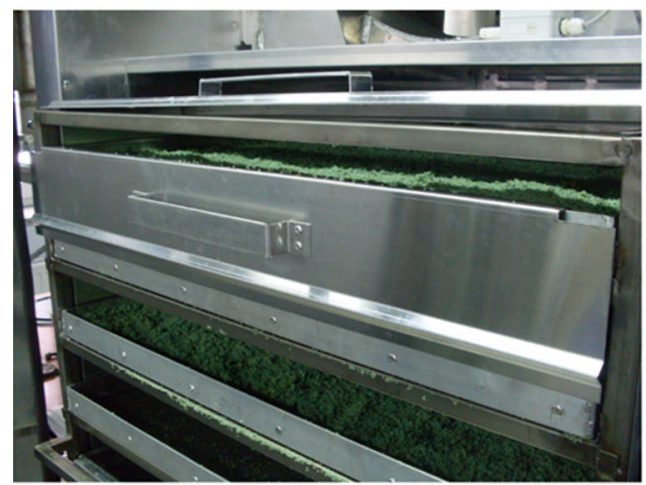

C

Fig. 4 Production of biological additives with copper as an example. a Biosorption of microelement ions from the solution in a column, b the column with enriched soybean meal after pumping out the

Table 2 Content of microelements in the formulations prepared by biosorption in a quarter-technical scale plant $( \pm \mathrm{SD}, N=3)$

\begin{tabular}{lll}
\hline Microelement & \multicolumn{2}{l}{ The content of microelement $(\mathrm{mg} / \mathrm{g})$} \\
\cline { 2 - 3 } & Raw soy bean meal & Enriched soybean meal \\
\hline $\mathrm{Cu}(\mathrm{II})$ & $0.065 \pm 0.004$ & $11.7 \pm 1.5$ \\
$\mathrm{Fe}(\mathrm{II})$ & $0.235 \pm 0.015$ & $11.9 \pm 1.5$ \\
$\mathrm{Zn}(\mathrm{II})$ & $0.054 \pm 0.005$ & $9.06 \pm 1.18$ \\
$\mathrm{Mn}(\mathrm{II})$ & $0.096 \pm 0.014$ & $5.92 \pm 0.77$
\end{tabular}

The multielemental analysis showed that the concentration of potassium ions in the solution after biosorption was $519 \mathrm{mg} / \mathrm{dm}^{3}\left(0.623 \%\right.$, expressed as $\left.\mathrm{K}_{2} \mathrm{O}\right)$. According to the Decree of the Minister of Agriculture and Rural

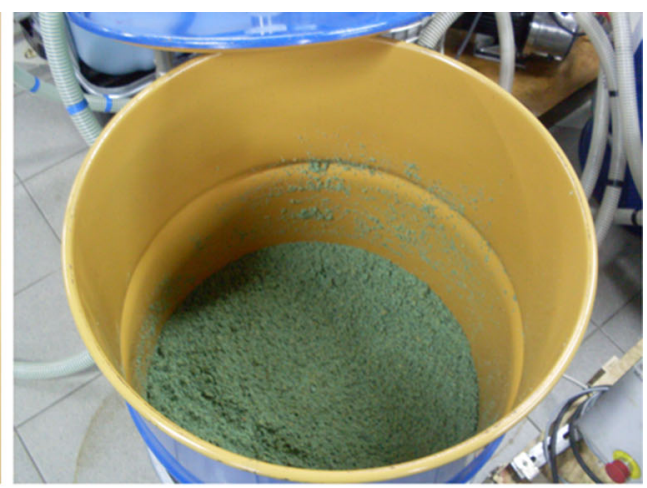

B

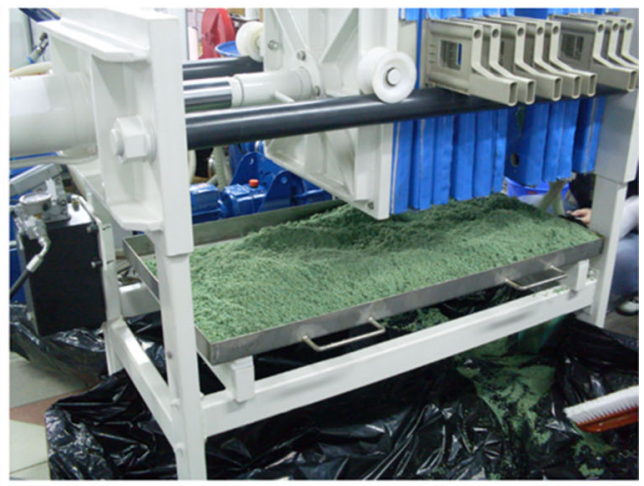

D

process solution, c the formulation with copper after mechanical drying in a filter press, $\mathbf{d}$ the preparation with copper dried on the shelves of the oven

Development of 18 June 2008, the content of potassium in a liquid mineral fertilizer should be greater than $1 \%$ in terms of $\mathrm{K}_{2} \mathrm{O}$ and greater than $0.5 \% \mathrm{~K}_{2} \mathrm{O}$ in a liquid mineral-organic fertilizer. The solution after biosorption can therefore be used as a base for the preparation of a liquid mineral-organic fertilizer, or used again in the next biosorption process after salts of microelements have been added to it in order to obtain a higher concentration of potassium.

\section{Preliminary economic analysis}

Currently, the annual production of compound feed in Poland is around 8 million tons, of which about $240,000 \mathrm{mg}$ are all additives (trace elements, enzymes,

Table 3 Composition of raw and enriched in microelements soybean meal

\begin{tabular}{lcccccccccc}
\hline $\begin{array}{l}\text { Microelement content } \\
(\mathrm{mmol} / \mathrm{kg})\end{array}$ & $\mathrm{Zn}(\mathrm{II})$ & $\mathrm{Cu}(\mathrm{II})$ & $\mathrm{Ca}(\mathrm{II})$ & $\mathrm{Mg}(\mathrm{II})$ & $\mathrm{K}(\mathrm{I})$ & $\begin{array}{l}\text { Sorbed } \\
\mathrm{Zn}(\mathrm{II})\end{array}$ & $\begin{array}{l}\text { Sorbed } \\
\mathrm{Cu}(\mathrm{II})\end{array}$ & $\begin{array}{l}\text { Released } \\
\mathrm{Ca}(\mathrm{II})\end{array}$ & $\begin{array}{l}\mathrm{Released} \\
\mathrm{Mg}(\mathrm{II})\end{array}$ & $\begin{array}{l}\mathrm{Released} \\
\mathrm{K}(\mathrm{I})\end{array}$ \\
\hline Soybean meal & 0.82 & 1.02 & 86.26 & 156.1 & 77.31 & & & 32.87 & 55.46 \\
Soybean meal $+\mathrm{Zn}(\mathrm{II})$ & 180.6 & 0.56 & 53.39 & 100.7 & 28.00 & 179.8 & & 28.82 & 34.27 \\
Soybean meal $+\mathrm{Cu}(\mathrm{II})$ & 1.42 & 183.4 & 57.44 & 121.87 & 30.00 & & 182.4 & 28.82 & 47.30 \\
\hline
\end{tabular}




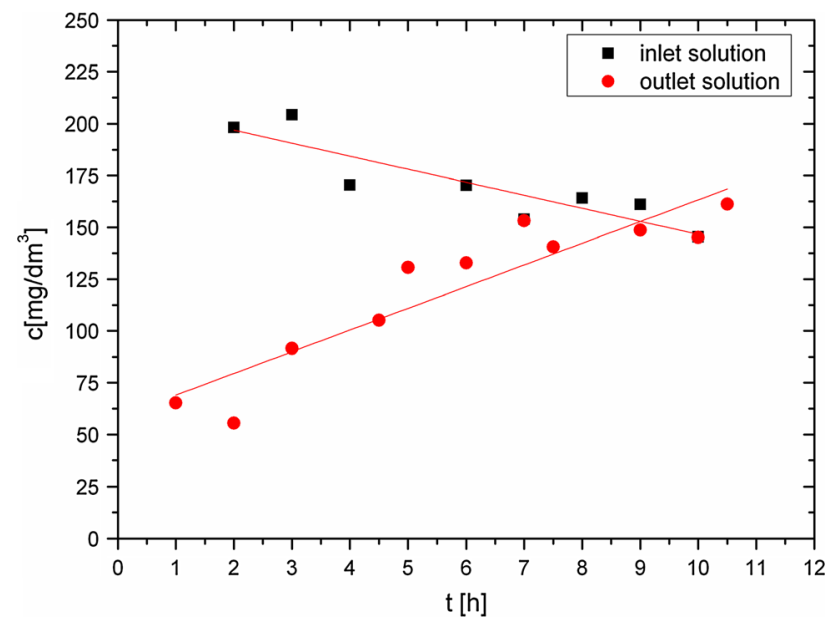

Fig. 5 Change in the concentration of $\mathrm{Zn}$ (II) in the feed solution and in the solution leaving the column

vitamins, etc.) (European Feed and Manufacturers' Federation 2012). Calculations for developing a new formulation based on soybean meal were performed on the example of the production of a 10-mg dietary supplement with copper.

\section{Estimation of the production cost of $10 \mathrm{mg}$ of a new formulation with copper}

The estimated cost of producing $10 \mathrm{mg}$ of a new formulation with copper is presented in Table 4.

This means that the price of raw materials needed to produce $10 \mathrm{mg}$ of a feed additive with $\mathrm{Cu}(\mathrm{II})$ is $\$ 8417$, which gives $\$ 0.84$ per $\mathrm{kg}$. To estimate the total cost of producing the additive, labor costs and depreciation of equipment should be taken into account in the calculation.

(a) Depreciation of equipment

The approximate value of the production system was $\$ 98,360$, including the equipment shown in Table 5A. Assuming that the period of the complete depreciation of the equipment is 5 years, the annual depreciation was assessed at $20 \%$. The daily depreciation of these devices was therefore estimated at \$53.9.

(b) Labor costs

The production cycle was assumed to take $8 \mathrm{~h}$ (1 batch: $7 \mathrm{~h}$ production process $+1 \mathrm{~h}$ for additional work and maintenance). This means that 3 batches/ day yield $50 \mathrm{~kg}$ of product. The installation is automated but requires maintenance. One person should supervise the process ( $24 \mathrm{~h}$ per day), and one additional person should monitor the end/start of the production of a batch of material ( $2 \mathrm{~h}$ per day). In total, service installation requires $800 \mathrm{~h}$ of work a month, which is performed by five people employed full-time each. It was assumed that the total labor cost of one person is $\$ 820$ gross. The total monthly labor cost of operating the system at 3 shifts is $\$ 4098$ gross, which yields $\$ 137$ per day.

The production of a single batch of $50 \mathrm{~kg}$ of the preparation lasts $8 \mathrm{~h}$. Assuming $8 \mathrm{~h}$ a day to produce three batches $(150 \mathrm{~kg})$, it is necessary to use $150 \mathrm{~kg}$ of soybean meal and $3.42 \mathrm{~kg}$ copper(II) sulfate(VI) pentahydrate. Table 5B summarizes the estimated daily cost of the production of a new biotechnological preparation based on soybean meal on the pilot quarter-technical scale.

The technical cost of producing $150 \mathrm{~kg}$ of the new formulation is $\$ 1003.42$. Therefore, the technical cost of producing $1 \mathrm{~kg}$ of preparation was assessed at $\$ 6.69$. The estimated market price should be approximately $150 \%$ of the technical cost, due to the expenditure of the enterprise and the profit margin of the manufacturer. Finally, the price of $1 \mathrm{~kg}$ of a new formulation of copper will be around $\$ 3.28$, which gives $\$ 3279$ for a 10 -mg preparation. This is the price that is about $40 \%$ higher than the price of inorganic salts. The price of the biosorption product is about 6 times lower in comparison with the price of $1 \mathrm{~kg}$ chelate (amino acid chelate Mintrex, offer by Novus, USA, and amino acid chelate Glystar, according to the offer from Arkop Ltd., Bukowno).

\section{Estimation of the cost of supplementation of $1 \mathrm{mg}$ feed with the new supplement}

The cost of the application of the new biological copper preparation to be used as a 1-mg supplement of poultry feed with this element was estimated at $\$ 1.67$ (demand: $8 \mathrm{mg} / \mathrm{kg}$ of feed), while that of fatteners amounts to $\$ 4.18$ (requirement: $20 \mathrm{mg} / \mathrm{kg}$ ) and that of goats-\$2.09 (requirement: $10 \mathrm{mg} / \mathrm{kg}$ ). Taking into account the contents of the trace elements in the preparation, approximately $0.5 \mathrm{~kg}$ of soybean meal, which is deducted from the cost of enriching the quantity of fodder for poultry by $\$ 0.31$, should be withdrawn from each $1 \mathrm{mg}$ of feed for poultry.
Table 4 Estimated cost of producing $10 \mathrm{mg}$ of a new formulation with copper

\begin{tabular}{lllllll}
\hline Factor & Inorganic salts & $\begin{array}{l}\text { Water } \\
\text { consumption }\end{array}$ & Soybean & \multicolumn{2}{l}{ Electric consumption } & \multirow{2}{*}{ Total cost } \\
\cline { 5 - 5 } & & & Process & Drying & \\
\hline Amount & $456 \mathrm{~kg}$ & $200 \mathrm{~m}^{3}$ & $10 \mathrm{mg}$ & $2.2 \mathrm{MWh}$ & $15 \mathrm{MWh}$ & \\
Cost $(\$)$ & 1053 & 316 & 6160 & 154 & 1050 & 8417 \\
\hline
\end{tabular}


Table 5 Estimation costs of equipment (A) and estimated technical cost of manufacture of $150 \mathrm{~kg}$ of the new preparation with copper (B)

\begin{tabular}{lrlll}
\hline A & & & B & Daily cost (\$) \\
\cline { 1 - 2 } Equipment & Cost $(\$)$ & & Components of cost & 92 \\
\hline Biosorbers (2) & 26,229 & & Soybean meal & 7.91 \\
Water treatment plant & 13,115 & & CuSO $_{4} \cdot 5 \mathrm{H}_{2} \mathrm{O}$ & 4.75 \\
Dryer & 8852 & & Water & 33.2 \\
Filter press & 32,787 & & Electricity & 54 \\
Tanks (2) & 1311 & & Depreciation & 137 \\
Membrane pump & 5574 & & Labor costs & \\
Centrifugal pumps $(2)$ & 2623 & & & 328.86 \\
Biomass trays (2) & 4590 & & & \\
Packing machine & 3279 & 98,360 & Total & \\
Total & & &
\end{tabular}

Similarly, the cost of the supplementation of feed for fatteners, taking into account the decrease in soybean meal, is $\$ 0.77 /$ per $1 \mathrm{mg}$ feed. Given that the current purchase price of $1 \mathrm{mg}$ of fodder for laying hens and fattening pigs is around $\$ 393$, the gross value of the new feed additive of the feed mix is less than $0.5-1 \%$.

The cost of the supplementation with the new copper preparation is approximately $20 \%$ lower than the cost of the use of copper chelate. These costs have been estimated for the production on a quarter-technical scale. On an industrial scale, the costs are highly likely to be lower.

\section{Importance of findings and barriers to implementation}

The application of micronutrient supplements that are not natural components of the diet (inorganic salts, organic chelates) significantly reduces the palatability of the feed. Furthermore, commercial feeds do not cause the enrichment of animal products with micronutrients (copper, manganese or zinc). Developed micronutrient feed components based on the biomass constitute the solution to the supplement animal diet with these elements. Moreover, the application of biological feed supplements enables biofortification of animal products (Witkowska et al. 2015).

The scaling up of the process should be preceded by some technological modifications of the installation, which could boost the process productivity, reduce energy consumption and hence lower the final costs. One of the ways to improve the present situation on a larger scale is the application of an alternative drier. The use of a fluidal drier instead of a heating chamber could reduce energy consumption by $40 \%$ and significantly bring down production costs.

A number of qualitative tests which have to be carried out may bar the implementation. The commercialization of the technology of the production of dietary feed supplements must be preceded by the analysis of the characterization and conditions of the application of the new products. Also additional safety and efficacy tests are obligatory.

The new eco-friendly approach to the production of micronutrient feed additives is a non-waste technology with a lower power consumption than that required by the conventional production. The new product and technology have a lower negative impact on the environment because the final product is fully biodegradable and no effluent is produced. Micronutrients in new preparations are supplemented in bioavailable form for animals, so there is no need to provide them in larger doses.

\section{Conclusion}

The pilot plant for the process of biosorption on a quartertechnical scale with two-column reactors was designed and constructed according to the principles of the eco-friendly effluent-free technology. The applicative parts of products and innovative biological feed supplements were produced for zoo-technical tests on animals (hens, goats and fatteners). The multielemental analysis showed a multiple increase in the content of each microelement in the biomass after biosorption. Formulations with $\mathrm{Zn}$ (II), $\mathrm{Cu}$ (II), $\mathrm{Mn}$ (II) and Fe(II) were manufactured and tested in terms of their utilitarian values on animals. The first trials on goats showed that the new formulation is characterized by a higher bioavailability to the animal, which results in a higher content of microelements in the products for humans (milk and cheese), thus becoming a new generation of biofortified functional food.

In order for the products to be marketed in the EU as feed additives, it is necessary to perform further studies on the safety and effectiveness of the preparations. Also, a complete analysis of physicochemical and biological properties of new preparations should be performed. On the basis of the preliminary cost analysis for the production on 
a quarter-technical scale, the estimated cost of the application of the new formulation of copper was approximately $20 \%$ lower as compared to the use of copper chelate in the compound feed for laying hens or poultry. The cost of the new feed additive constitutes $0.5-1 \%$ of the cost of feed.

Acknowledgments The work was supported by the Polish National Centre for Research and Development, under Grant No. N R05 0014 10.

Open Access This article is distributed under the terms of the Creative Commons Attribution 4.0 International License (http:// creativecommons.org/licenses/by/4.0/), which permits unrestricted use, distribution, and reproduction in any medium, provided you give appropriate credit to the original author(s) and the source, provide a link to the Creative Commons license, and indicate if changes were made.

\section{References}

Aytar P, Gedikli S, Buruk Y, Cabuk A, Burnak N (2014) Lead and nickel biosorption with a fungal biomass isolated from metal mine drainage: Box-Behnken experimental design. Int J Environ Sci Technol 11:1631-1640

Blanusa M, Varnai VM, Piasek M, Kostial K (2005) Chelators as antidotes of metal toxicity: therapeutic and experimental aspects. Curr Med Chem 12(23):2771-2794

Chojnacka K (2010) Biosorption and bioaccumulation-the prospects for practical applications. Environ Int 36:299-307

Chojnacka K (2013) Quo vadis chemistry for agriculture? From feed additives and fertilizer components to algal extracts. Przemys Chem 92:732-735

Chojnacka K, Gorecki H, Zielinska A, Michalak I (2009) Technology of the production of biological mineral feed additives based on the biomass of algae. Przemys Chem 88:634-639

Davis T, Volesky B, Mucci A (2003) A review of the biochemistry of heavy metal biosorption by brown algae. Water Res 37:4311-4330

Doshi H, Ray A, Kothari I (2007) Bioremediation potential of live and dead spirulina: spectroscopic, kinetics and SEM studies. Biotechnol Bioeng 96:1051-1063

Hood A, Chopra M, Wanielista M (2013) Assessment of biosorption activated media under roadside swales for the removal of phosphorus from stormwater. Water 5:53-66

Jauberty L, Gloaguen V, Astier C, Krausz P, Delpech V, Berland A, Granger V, Niort I, Royer A, Decossas J (2011) Bark, a suitable biosorbent for the removal of uranium from wastewater-from laboratory to industry. Radioprot 46:443-456

Kanagaraj J, Senthivelan T, Panda RC, Kavitha S (2014) Eco-friendly waste management strategies for greener environment towards sustainable development in leather industry: a comprehensive review. J Cleaner Prod 89:1-17
Kratochvil D, Volesky B (1998) Advances in the biosorption of heavy metals. Trends Biotechnol 16:291-300

Mansuri N, Mody K, Basha S (2014) Biosorption of ammoniacal nitrogen from aqueous solutions with low-cost biomaterials: kinetics and optimization of contact time. Int J Environ Sci Technol 11:1711-1722

Michalak I, Chojnacka K (2009) Edible macroalga Ulva prolifera as microelemental feed supplement for livestock: the fundamental assumptions of the production method. World $\mathrm{J}$ Microbiol Biotechnol 25:997-1005

Michalak I, Chojnacka K, Witek-Krowiak A (2013) State of the art for the biosorption process-a review. Appl Biochem Biotechnol 170:1389-1416

Mishra A, Dubey A, Shinghal S (2015) Biosorption of chromium(VI) from aqueous solutions using waste plant biomass. Int J Environ Sci Technol 12:1415-1426

Pan X, Wang J, Zhang D (2005) Biosorption of Pb(II) by Pleurotus ostreatus immobilized in calcium alginate gel. Process Biochem 40:2799-2803

Podstawczyk D, Witek-Krowiak A, Chojnacka K, Sadowski Z (2014) Biosorption of malachite green by eggshells: mechanism identification and process optimization. Bioresour Technol 160:161-165

Reverberi AP, Dovì VG, Fabiano B, Maga L (2009) Using nonequilibrium biosorption column modelling for improved process efficiency. J Cleaner Prod 17:963-968

Tuhy Ł, Samoraj M, Chojnacka K (2013) Evaluation of nutrients bioavailability from fertilizers in in vivo tests. Int J Eng Sci $1: 10-13$

Tuhy Ł, Samoraj M, Michalak I, Chojnacka K (2014) The application of biosorption for production of micronutrient fertilizers based on waste biomass. Appl Biochem Biotechnol 174(4):1376-1392

Verma DK, Hasan SH, Ranjan D, Banik RM (2014) Modified biomass of Phanerochaete chrysosporium immobilized on luffa sponge for biosorption of hexavalent chromium. Int $\mathrm{J}$ Environ Sci Technol 11:1927-1938

Witek-Krowiak A, Podstawczyk D, Chojnacka K, Dawiec A, Marycz K (2013a) Modelling and optimization of chromium(III) biosorption on soybean meal. Centr Eur J Chem 11:1505-1517

Witek-Krowiak A, Chojnacka K, Podstawczyk D (2013b) Enrichment of soybean meal with microelements during the process of biosorption in a fixed-bed column. J Agric Food Chem 61:8436-8443

Witkowska Z, Chojnacka K, Michalak I (2013) Application of biosorption in the production of innovative feed supplements: a novel method. Ads Sci Technol 31:421-431

Witkowska Z, Michalak I, Korczyński M, Szołtysik M, Świniarska M, Dobrzański Z, Tuhy Ł, Samoraj M, Chojnacka K (2015) Biofortification of milk and cheese with microelements by dietary feed bio-preparations. J Food Sci Technol. doi:10.1007/ s13197-014-1696-9

Zhang Z, Shi D, Ding H, Zheng H, Chen H (2015) Biosorption characteristics of 1,8-dihydroxy anthraquinone onto Aspergillus oryzae CGMCC5992 biomass. Int J Environ Sci Technol 12:3351-3362

Zielinska A, Chojnacka K (2010) Clean technology of the production of feed additives based on Spirulina maxima blue-green algae. Przemys Chem 89:590-593 